\title{
Netizens' Psychological Behavior Analysis under Information Technology Background
}

\author{
Hui ZHI \\ Wuhan Donghu University \\ Wuhan,Hubei, 430212,China
}

\begin{abstract}
With the growing size of China's Internet users, many network hot events happen in recent years, public opinion gradually formed an unstoppable tide network, its enormous power not only swept the virtual space, and continued to influence every corner of the community, causing a growing social unrest. The complicated behavior of Internet users has become the focus of attention, and it attracted academic attention, setting off a wave of research followed.
\end{abstract}

Keywords-Information Technology; Users' behavior; Psychological Problems

\section{INTRODUCTION}

Since the 1990s, China's entry into the Internet field since the network continues to affect social life and subverts the traditional social structure. Network with its many features is becoming concentrated field of public opinion and catharsis mouth, or the size of their network public opinion brewing hot events and promoting social outbreak caused a huge shock. First, the number of Internet users in recent years is showing a significant leaps and bounds, which is showing the diversity of users' behavior trend. According to China Internet Development Statistics Report Network, as of October 31, 1997, the number of Internet users in China is only 620,000 . As of the end of June 2010, Internet users in China reached 420 million, ranking first in the world, the number of Internet users becomes anxious expansion that leads users a civil society that cannot be ignored important force. But, on the other hand, unorganized, low threshold, mixed groups of Internet users form a threat to social stability. Internet users are no longer satisfied with access to information, communication, entertainment and other simple functions to use, when there is a network event, showing the diversity of the people behavior characteristics and trends. Second, once the network has hot events in recent years, public opinion has great social influence on showing spurt state. Internet users in China since 1999 are to protest against the NATO atrocities end of 2006, the network has been found in some of the more influential of hot events, but overall a smaller number. The 2007 was the first peak of the network public opinion hot events, in 2007 is a turning point to the present. The network of public opinion straightens up hot events showing the trend of large-scale outbreak of a series of large-scale, strong impact, continuing a long time, the network of public opinion hot events and popular social stability caused varying degrees of impact. A large number of Internet users, diversity of users of network behavior and public opinion spewing hot events become a social reality of the Internet era. In the event of a network of public opinion hot events, evolution, extinction process, heroic individual users or groups of emerging public style has become a trigger and an important force to promote network events. Active or casual, silent or positive, calm, or impulse, whim or strategizing, users mix network behavior in the noisy world of seemingly complex, chaotic, yet strong impetus to the network of public opinion hot events intensified, unstoppable. Once again, it set off waves and trigger social network fluctuations even unrest. Internet users behavior exhibited more than a network of public opinion forces the hot events in recent years been repeatedly reflected. "Chinese netizens have public energy as the 'new opinions class', which is forming a real impact virtual 'pressure group"'

\section{TYPE AND CHARACTERISTICS OF USERS' PSYCHOLOGY}

In this paper, the integrated use of journalism, sociology, theory and research communication studies and psychology are starting from the basic theory of psychological research users to explore the network of public opinion incident, netizens' psychological type and characteristics. Study in China particular context and environment, psychology and the intrinsic link users' network public opinion, draw psychological necessity of network public opinion based on users guide. Then, based on the analysis of network public opinion, it is to guide users' mental achievements and the problems and causes of problems, and finally propose a network-based public opinion to guide users' psychological strategies for emerging issues. Specifically it is involved in the research agenda setting theory, group pressure, and other related academic gatekeepers, while supporting the latest case of Internet public opinion, in order to explore the theory of the case, from a theoretical analysis of the case, and try to make network boot strategy proposed public opinion more efforts.

Psychological and network users guiding public opinion has become a hot topic of current research, but also is the emergence of a number of domestic and international research on these. Studies are mostly from sociology, communication studies and other point of view, the network of public opinion to guide and separate users' psychological research. The article is by studying the psychology of 
Internet users and Internet public opinion of internal relations, it will guide the establishment of a network of public opinion research on the psychological basis of Internet users, which is quite relevant and practical.

This study is based on the psychological characteristics of Internet users, type and impact of learning theory and research methods of communication, psychology, sociology and other disciplines. It has a full utilization and absorption of foreign-related data and existing research, public opinion research network users psychological guide strategy. The main methods are:

It is the literature research. We should study and analyze large collection of relevant literature and masters, conclude the users of the network public opinion psychological type and characteristics of induction, propose strategies to guide public opinion for our network to provide theoretical support.

It is the case analysis. This article will be selected during the analysis of public opinion and many other hot events will be classified by network analysis to the role of public opinion in these networks users psychological events, propose strategies to guide public opinion for our network to provide examples for reference.

It is the comparative analysis. Through the contrast to the attention of Internet users in the event of network public opinion in different periods, we should analyze changes in public opinion in my network users' psychology in order to put forward a more targeted strategy to guide users on the network public opinion psychology.

\section{USERS' CONNOTATION AND PSYCHOLOGICAL CHARACTERISTICS}

In recent years, the network was booming trend of public opinion, positive or negative influence is growing, which attracted the attention of the community. And users of public opinion as the main network is active on the Internet to speak of individuals or groups, the network events communicators and recipients, they are concerned about all aspects of life, including social and livelihood, official corruption, social injustice, the focus of Internet users who can excite nerves of things are of concern to them. By posting them, with forensic investigation and even research, they will impact the development process and the network of public opinion. Due to the huge and growing number of Internet users, their psychological needs and characteristics increasingly become the focus of research. As for the Internet users, although the psychological connotations users have psychological concern, but so far, the domestic industry has not yet unified their argument. But I believe that Internet users and psychological things contains two concepts of social psychology, so to explore the psychology of users can define these two aspects. With the increase of Internet users in the study, the academic definition of Internet users has a variety of claims; they have their different perspectives on the definition of Internet users. From the perspective of network communication, "netizens" refers to Internet users, the person is not only the letter but also the recipient disseminators of information, and they receive information through a lot of ways and often browse through microblogging, BBS forums, QQ chat, e-mail and other ways to publish and disseminate information. From a sociological point of the network, he believes that the community is often interactive "surfers" that formed a human community, people put these "surfer" called netizens, and they should be involved in the community and get a legitimate normal accepted through normal channels with the effectiveness of the account name and email address. In this paper, starting from the network of public opinion, "netizens" may be considered based on the Internet for the media, through the publication of opinions and comments, and the majority of users interact, thus promoting the development of the Internet's agenda. Its meaning is a positive statement on the Internet users who are individuals or groups and who are communicators and recipients of network events, they are concerned about all aspects of life, including social and livelihood, official corruption, social injustice and other users who can excite nerves of things that have the focus of their attention. By posting them, forensic investigation, they will have the impact on the development process and the network of public opinion. In short, whether the subject is an individual or group, users with network activity are an important and indispensable part of the network of public opinion.

\section{PSYCHOLOGICAL TYPE OF USERS}

From the point of view Famous American humanistic psychologist, the human can be divided into three categories, seven levels: basic needs, including physiological needs, safety needs; psychological needs, including the need for love and belonging, esteem needs, cognitive needs, aesthetic needs; the need for self-realization is the highest level, humans are unique, but also the highest level of human pursuit. Everyone will want to exist in society something being seriously and realize their value, but in the intense social environment, they have increasing pressure of human existence, the realization of human self-worth is difficult and convenient and virtual network just meet the requirements of users pursuit of self-psychology. Internet users can freely communicate, obtain identity and a sense of accomplishment, and many that cannot be achieved in reality can get psychological satisfaction. In many events of network of Internet, users by focusing on the development of the incident, the pursuit of the truth, finally resolved to make the event to get everyone's approval, we can say this is the victory of a civilian population. And users' self-worth, selfsatisfied can achieve.

That people have a curiosity to explore the psychology, so do the users. In front of the confusing things, users search for the truth of psychological particularly evidence. Exploring the truth of the matter is people's psychological needs, in this psychological drives, users seek psychological truth that would go viral. With the occurrences of the search engines, users are informed of diverse and fast means of information, they will also have a broader search. Network events are pursued by means of Internet users to promote the spirit of the course of events.

\section{A. The expression way of psychological decompression}

China is undergoing social transition, fast-paced life, intense competition, often encounter some setbacks and 
things, there is a certain gap between the expectations of social reality and the public, the people in the real world will be more and more often mental anxious. As an inevitable reflection in the water scene from the shore, cyberspace is not real, but the issue of network communication is no not from the real world.

\section{PSYCHOLOGICAL CHARACTERISTICS OF THE INTERNET USERS IN THE NETWORK GROUP}

Internet users studied particularity that personality psychology, psychological characteristics of Internet users in the population are worth exploring. Many times users are also in certain groups; to express their views may also be limiting pressure within the groups, in this case, users of psychological orientation are not the same. Some Internet users become the event of the "opinion leaders", and some groups of users become blind obedience, so I explore the Internet users in the group of psychological pressure from the following two aspects. First, it is the "opinion leaders" mentality in the Internet users; the second is the population of Internet users in the herd mentality.

Psychoanalysis on "opinion leaders" group of Internet users in the network

The Classical concept of opinion leaders of Communication originated in the 1940s. When the mass media was to pass information to the public, there is a secondary spread of the phenomenon (the media - opinion leaders - audience), which is issued by the mass media for information and does not completely reach each audience immediately, but it may be part of opinion leaders acceptance. The opinion leaders through their own analysis of the information are to determine screening process, adding their own views opinions, then this information selectively communicate to other audiences (mostly less mass media contact information), in order to influence other audiences the views or attitude and behavior information, and may form public opinion in a small area.

"The mass refers individuals in the population due to the physical presence of mind or imagination to social pressure and pressure groups on perception, judgment, belief and behavior. That is consistent with the majority of the population, or to act according to the popular practice of the phenomenon." visible mass mentality stems from the strong influence of individuals and groups with the lack of information about the users. Many events are posted to the network, it is first attracted the attention of Internet users. And then there will be a message thread, in this case, if the event is to have enough focus topic, it will attract more people to participate in the spread of this event, in such the process, it will be clear factions, support and the opposition. Many Internet users are unwittingly getting in, and I do not know the reason of the event, some are claiming to be the event of an insider or a distinctive view of "opinion leaders" who played a leading role, which also lacks commercial operation. And some users know the truth of the incident and they only scattered fragments of Interpretation, the network provides only limited information, they will naturally have several options. The first may be only a spectator, which does not make any comments; second, Internet users choose to join one of the strong points of view, because in the absence of effective information is provided. Users are more willing to support the view or strong side, so for them it will be more confidence and security forces, the group is powerful; third, there such users they believe that "the truth often lies in the hands of a few."

\section{CONCLUSIONS}

History is the history of the growth of the Internet users, so the study of psychology and behavior of Internet users are very important and has great practical significance. But, to deal with critical network events also depends on the government, then the government should be how to deal with network events? Government should correctly deal with positive emotions of Internet users, Internet users mobilize, cut the users as a scourge. The Government should take the initiative to set the agenda for the right to speak. Government is the main social management; it holds a wealth of information that can be timely and efficient setting the news agenda. When an event may cause the occurrence of hot Internet users, the government in the first time is to capture the relevant information, in accordance with the initiative to set the news agenda for the development of the event. It can strive to make the government's response measures to attract the attention of visitors, influence public opinion and online Internet users' emotions, so that the issue has most favorable direction toward progress. Media literacy training users are prompting users to be rational without blind conformity and drift. Faced with numerous networking events, users cannot express their emotions in heart, what really needs to do is able to use the case to the topic or want to express their own interests in the matter concerned by the expression of the specific context and the interpretation of it. It should select the appropriate word of expression, rather than the great length of the abstract chaos regardless of the actual views, the public opinion should establish a network of monitoring with early warning systems.

References

[1] Zhou Haihong. Psychological Analysis (Lecture Outline) [A]. Central Conservatory of Music Institute of .2003 'Beijing First National Music Appreciation Teaching Symposium [C]. Central Conservatory of Music Studies the: 2003: 2.

[2] Jiang Weiwei. Students consumer psychology and consumer behavior problems and countermeasures [J] vicissitudes, 2008,03: 197-198.

[3] Zhou Ping. Modern enterprise human resource management information problem investigate [D]. Shandong University, 2006.

[4] Lu Lijue. Study teaching college information management problem [J] China Higher Education Research, 2004,01: 86-87.

[5] Zhang Guoping. ERP accounting information age problems and countermeasures [J] Friends of Accounting (on Xunkan), 2010,07: 55-56.

[6] Wang Xiaodan. Enterprise information problems and countermeasures [J] technology rich Wizard, 2013,08: $38+83$. 